\title{
A RETROSPECTIVE: DESIGNING A CAREER DEVELOPMENT PREPARATION COURSE IN A MANDATORY COOP ENGINEERING TECHNOLOGY PROGRAM
}

\author{
Allan MacKenzie \\ Management Program Chair \\ McMaster University, School of Engineering Technology \\ Hamilton, Ontario, Canada \\ mackenza@mcmaster.ca
}

\begin{abstract}
In the 2012-2013 academic year McMaster's University School of Engineering Technology (SET) introduced a Professional Workplace Practices course (GENTECH 2PW3) within the Bachelor of Technology (B.Tech) Program. The course uses an experiential learning approach to instill key employability skills required to successfully participate and progress in today's dynamic engineering and technology organizations. It is a second year academic prerequisite before a student can commence the B.Tech Program mandatory 12 month coop work experience. The course is delivered and supported by a multidisciplinary team that includes faculty members, career development practitioner, who serve as instructional assistants, and the McMaster Engineering Career and Coop Services (ECCS) department. For the purposes of knowledge sharing, this paper will discuss the GENTECH 2PW3 course structure, delivery, administration, and outcome results for 470 students from the last three cohort years.
\end{abstract}

Keywords: Cooperative education; development; experiential learning; co-curricular education, work experience; career preparation; professional skills; engineering technology program

\section{INTRODUCTION}

This paper will discuss a second year Professional Workplace Practices course (GENTECH 2PW3) that was introduced into the Bachelor of Technology (B.Tech) program at the McMaster School of Engineering Technology (SET) in the fall of 2012. The purpose of this course is to equip students with vital knowledge and tools necessary to obtain and retain mandatory coop work experiences and achieve successful employment after graduation. The course uses an experiential approach to career advancement techniques to help students and graduates excel as professionals in engineering technology roles. For the purposes of knowledge sharing, this paper will examine the GENTECH 2PW3 course development, course structure, student and instructor feedback, and administrative challenges from the last three cohort years.

B.Tech is a skills-based engineering technology and management program at the university level. The program is a partnership between McMaster's University Faculty of Engineering and Mohawk College's School of Engineering Technology. The direct-entry from high school B.Tech program streams (i.e. areas of specialization) are: Automotive and Vehicle Technology, Biotechnology, and Process Automation Technology. The B.Tech Partnership builds on the academic strengths of both institutions, each of which have a solid concentration of expertise and experience in engineering and technology education. The aim is to produce graduates who will have considerably more theoretical, breadth and depth in their area of technology than graduates of college technology diploma programs. On the other hand, there is more emphasis on applications of specific technologies than a corresponding engineering program. Since 2007, the B.Tech program has prepared graduates for careers in hands-on engineering technology applications such as, production, manufacturing, construction supervision, and project management. Graduates are awarded three academic credentials: a McMaster University Bachelor of Technology degree, an Advanced Technology diploma and, a Business Management Certificate from Mohawk College [1].

Several components of the B.Tech curriculum are unique compared to other engineering technology programs in Ontario. The program integrates business and management with technical education. Approximately $25 \%$ of the overall program curriculum is composed of the mandatory GENTECH courses, which are delivered to students across all three technical program streams. This curriculum comprises business fundamentals similar to foundational courses found within most curricula of business administration degree programs at the college level. 
The other unique aspect of the B.Tech program is its mandatory 12-month coop work experience. All students must complete a minimum of 12-months paid coop work experience in their industry specialization as part of the academic requirement for graduation. Experiential workplace learning brings about a number of benefits, as reported in the research literature. These include, increased disciplined thinking, taking personal responsibility for learning, improved problem-solving skills, overall improved performance in the classroom, increased commitment to educational goals, and increased ability to finance their education [2]. Overall, this unique program feature helps students build transferrable and technical skills essential for career success.

The recommended approach for a B.Tech student to complete his/her mandatory 12-month cooperative education is shown in Figure 1. The first is a summer fourmonth work experience, after completing level 2B of coursework. The second is either one eight-month or two four-month work experiences during winter and summer after students complete level 3B of coursework. If a student is unable to complete a 4-month placement in any of the earlier time periods, they have the option of completing a four-month coop in the summer after level 4A. Students, who have not completed their 12 months of coop after level 4A, are blocked from enrolling in level 4B courses until they have completed all the mandatory coop workplace experience requirements.

\begin{tabular}{|l|l|c|c|}
\hline & Fall & Winter & Summer \\
\hline \hline Year 1 & Level 1A & Level 1B & \\
\hline Year 2 & Level 2A & Level 2B & Co-op \\
\hline Year 3 & Level 3A & Co-op & Co-op \\
\hline Year 4 & Level 3B & Level 4A & \\
\hline Year 5 & Level 4B & & \\
\hline
\end{tabular}

Figure1: B.Tech Program Structure

Before the GENTECH 2PW3 course was introduced in 2012, students were required to complete a mandatory eight hour workshop-based, non-credit coop preparation course (ENG 1EE0) delivered by the Engineering Coop and Career Services (ECCS) department. The course employed a lecture format to briefly cover topics in job search, cover letter and resume writing, and interview preparation. Generally, it was delivered in either, two four-hour classes on Saturday or four two-hour classes during the evening. There was no grade assigned and the only required deliverable was a cover letter and a resume package that met ECCS approval to participate in the mandatory cooperative education component of the B.Tech program.
A complete review of the B.Tech 4-Year GENTECH curriculum was undertaken in 2011, leading to significant changes, including course modification and the reordering of course delivery within the program, along with the addition of new courses. One of key initiatives from this review was a commitment to integrate career development into the academic curriculum to support the mandatory cooperative education outcomes students are required to achieve for graduation. This led to the creation of the GENTECH 2PW3 Professional Workplace Practices credit course. Career development courses for academic credit are well established in many leading American universities in response to the student need for a more knowledgeable approach to career development issues [3]. The objective was to establish a rigorous core course aimed at enriching the career development experience for B.Tech students and support their integrated management education. A clear short-term objective was also to provide students with the necessary knowledge and skills to successfully fulfill their mandatory cooperative educational program requirement. Kolb’s experiential learning model [4] is incorporated into discussions, exercises, weekly workshops, final exam and assignments. The course was approved by the faculty of engineering undergraduate curriculum review committee and the University Senate for its inaugural delivery in fall 2012 (level 2A).

\section{COURSE DESCRIPTION}

\subsection{Learning Outcomes and Structure}

2.1.1. General Overview. The learning outcomes and course structure for GENTECH 2PW3 was developed in consultation with industry advisors from B.Tech's Professional Advisory Committees from each of the three technical streams. The B.Tech Executive Director and Management Chair provided subject matter expertise, as they both have extensive talent acquisition experience and have held senior human resource management positions prior to working at McMaster. Collaboration was also sought with the Manager of Engineering Coop and Career Services (ECCS) and the career advisors within the department.

The specific learning outcomes for GENTECH 2PW3 Professional Workplace Practices course are:

- Prepare a personal job search plan, including troubleshooting strategies to deal with coop and/or employment acquisition challenges and obstacles.

- Create a personal career marketing package (cover letter, resume, references) that meets current recruiting and industry standards.

- Identify strategies to network and make contacts that could lead to employment. 
- Prepare and practice informational and mock employment interviews in order to present oneself as a confident professional.

- Demonstrate knowledge with the policies and procedures associated with the McMaster University Engineering Coop Program, including the recruiting process and timelines, and the use and application of campus recruitment tools/systems.

- Demonstrate knowledge and application of the principles of professionalism and code of conduct among practicing technical professionals.

To achieve these outcomes, GENTECH 2PW3 was structured as an experiential workshop type of course, with common instructional materials and activities provided to all students in a 13-week term. The course delivery structure is typically one 60-minute class and another 120-minute class (a total of three hours per week). Generally, the one-hour class is used to deliver course material in a lecture style format and the two-hour class is set up as a workshop, with students actively participating and reflecting on exercises and activities related to the course topics for the particular week.

Our initial goal was to have class sections no larger than 50 students in order to facilitate the earlier described active learning approach. Due to timetable constraints, however this was not always possible. In 2013 and again in 2014 one section had 70 students enrolled, which was not ideal. To deal with this issue in 2013, two instructors were assigned during the two-hour workshop class. This allowed them to circulate throughout the classroom and interact one-on-one with the students. This approach was so successful, that the program finally approved and budgeted for the hiring of two professional career development practitioners as part-time Instructional Assistants to support the instructors and students across all the course sections starting in 2014.

The McMaster Engineering Coop and Career Services (ECCS) department is also actively involved with providing direct course support during the term. Career development staff facilitate two interview skills workshops, provide hands-on navigation training on the campus recruiting platform (OSCARplus), role-play as recruiters during one-on-one mock interviews that are digitally recorded with every student and provide individual feedback to help students improve their career package materials. After the GENTECH 2PW3 course is completed, ECCS connects students with employers and continues to provide individual career planning support throughout their undergraduate program.

Various course resources are used to support the students with learning the course material, including a free 112 page workbook; "Advanced Techniques for Work Search" developed by the Government of Alberta Employment \& Immigration Department. The workbook offers detailed information and exercises to help individuals in post-secondary education to improve their career development strategies. The workbook is supplemented with extra material on specific topics areas, such as a list of action verbs, guides on professional interview attire, common interview questions, etc. Instructors are required to use a common set of lecture slides when presenting the course material and these are available for the students to download from the online learning management system (Avenue to Learn). The exercises and experiential activities used during the workshop are also mutual across all the sections to help ensure a consistent learner experience. The previous two years there was a required e-textbook, "Six Steps to Job Search Success," from Flatworld publishing. The textbook is now used as recommended resource for the students.

The GENTECH 2PW3 course curriculum has been modified each year based on feedback of students, instructors and ECCS personnel supporting the course. The current course structure and topics are described in sections 2.1.2 to 2.1.6.

\subsubsection{Weeks 1-2: Introduction and Self-Assessment.} The goal at the start of the course is to give students a realistic understanding of the competiveness involved in the job search and hiring process as they are generally naïve about the amount of time, dedication and persistence required to achieve a successful workplace coop or career position. To help illustrate some of these real-life constraints the students are led through a resume sorting exercise. This experiential activity demonstrates how quickly recruiters make decisions about applicant career materials and what is important from their point of view during the initial screening stage.

The students also complete a number of paper-based and online self-assessment exercises to help identify their explicit skills and employability attributes. The students are facilitated through a process to converge these materials into specific accomplishments. The outcome of this process is to give students a language to clearly articulate what they have done and the results achieved. These accomplishment statements can be included in resumes and cover letters or used during interviews when they need to describe their accomplishments concisely and convincingly to potential employers.

\subsubsection{Weeks 3-5: Career Marketing Package.} Instructional topics include the development of a customized job specific cover letter and a high-impact resume that provides a summary of skills, accomplishments, training, work and volunteer experiences and extracurricular activities targeted for workplace coop opportunities. A detailed career marketing package rubric is circulated to the students beforehand so they understand the format and depth of 
content expected for their resume and cover letter. The students choose from a selection of nine job postings similar to those employers have used in the past to attract B.Tech students for coop positions. The students then use the selected job posting to develop a personalized cover letter and resume tailored to the particular posting for their career package assignment. Detailed examples are provided on what to include in each of the major areas of the resume, such as, summary of qualifications, education, academic awards, scholarships, additional relevant skills, work and/or volunteer experiences, and extracurricular activities.

The weekly workshops during these weeks are focused on helping the students refine their personal accomplishments statements and resume format. Students complete a similar experiential activity as the earlier resume sorting exercise, but now focused on cover letters. This exercise again helps the students understand key elements sought after by recruiters and hiring managers. Students also complete a mapping exercise to further their understanding of how to relate their experiences to the employer job requirements. Finally, they work in triads conducting peer reviews using the assignment rubric to qualify discussion feedback to help each other improve their career package materials.

2.1.4 Weeks 6-8: Interviews. Students are taught what to do before, during and after an employment interview. Focus is given on how to approach different types of interviews, as well as the types of questions and how to best prepare answers for them. Students prepare for behaviour descriptive type questions based on STAR (Situation, Task, Action, Result) method to describe their accomplishments. They also learn how to conduct a successful informational interview to learn more about professions, organizations and industries.

Two interview workshops are facilitated by ECCS advisors during the two-hour class times to provide students with the opportunity to practice and get feedback on their interview skills. The students are divided into small groups of seven to ten members to practice answering typical interview questions and receiving feedback from their peers and the facilitator. It is well documented in the literature that there is a positive relationship between interview coaching and interview performance. For example, in one predictive validation study, researchers used scores from a situational panel interview from a sample of 146 public safety job incumbents. Predictive validity and reliability was observed to be higher in a sample of coached interviewees compared to a sample of uncoached interviewees [5]. Students are also encouraged to practice their interview skills outside of class using the InterviewStream, which is a third party software provided under license by the McMaster University Student Success Centre. This interview preparation software gives students access to thousands of pre-recorded questions in order to create a customized mock interview for practicing their responses using a computer, laptop or tablet device.

2.1.5 Weeks 9-11: Job Search Process. The focus in weeks 9-11 is placed on successful job search strategies, using both traditional and online resources. Further emphasis is placed on how to use the LinkedIn platform for job search and networking. In addition, students are guided through a specific troubleshooting process to help inform them when their job search breaks down and various strategies to get it back on track.

During the workshop sessions students write and roleplay a 20-second personal profile with their peers that can be used at professional networking events. They create a personal LinkedIn profile and are required to seek connection invitations from all the course instructors and IA's to jump-start the building of their professional network. A member of the ECCS runs a computer lab on how to navigate the OSCARplus system, which is McMaster University's online career portal. This platform provides support for all the career development, recruitment and experiential education opportunities for students on campus. Lastly, two senior level students come into each section and share their personal challenges of the coop job search and insights from their workplace coop experiences.

2.1.6 Weeks 12-13: Professionalism and Career Development. The final phase of the course focuses on how to successfully transition into the workplace and how to make a positive impression in the first ninety days. Topics include how to successfully manage conflicts and successfully work with difficult colleagues; establishing good communication with superiors; workplace privacy and confidentiality; professional ethics, organizational rules and code of conduct protocols. The course concludes with examining strategies and techniques for personal career management and lifelong learning to stay marketable and professional readiness for future jobs.

The workshops concentrate on ethics and professionalism where students analyze real-world scenarios from engineering technology workplaces and explore expectations of behaviour through the lens of professionalism and organizational codes of conduct. They also complete a number of discovery exercises, which explore and reflect on the impact of personal reputation management, accountability and building and maintaining a professional network. Another important aspect of their learning in the final weeks involves how to avoid workplace coop faux pas, which could lead to job termination. 


\subsection{Assessment of Learning}

2.2.1 Career Package Assignment (25\%). The purpose of the assignment is to provide students with an opportunity to develop an ethical, error free professional cover letter and resume (career package) that markets their unique characteristics for preferred engineering coop and technology employers. Each student is given detailed written feedback about their career package by an Instructional Assistant and the grade is assigned by the instructor using a detailed rubric to ensure a common frame of reference. Students are also offered a "Second Chance Option” with this assignment. They can revise their career package after receiving detailed feedback and their assignment grade. Interested students must meet inperson with an ECCS Career Advisor to discuss specific strategies to improve their career package before resubmitting the assignment. The revised mark is an average of the original submission and the final submission grade. The purpose of the second chance option is to encourage students to improve their career package, which will make them more effective in marketing their unique characteristics to coop engineering technology employers.

2.2.2 Informational Interview Report (10\%). The purpose of this assignment is to help students gain practical insight into the steps required to be successful in their field of interest; acquire knowledge of the day-to-day responsibilities of the type of positions students may be interested in; develop confidence in interacting with industry professionals; and provide opportunities for the student to develop professional contacts in their field of interest. The informational interview is graded by one of the Instructional Assistants using a rubric to ensure consistent grading for content and clarity for the specific assignment deliverables.

2.2.3 Mock Interview Assignment (20\%). The purpose is to provide students with an opportunity to demonstrate that they have mastered fundamental interviewing skills needed to increase their likelihood of winning a coop job with engineering technology employers. Students prepare for their mock interview based on the same example job posting they previously used for the career package assignment. They are expected to research the company and prepare a few questions they can ask the recruiter during the interview.

The ECCS career development staff act as recruiters and ask each student a number of behavioural-based interview questions for 15 minutes. The students are given appropriately 5-minutes at the end of the interview to ask insightful questions based on their personal research of the company. After the completion of the interview, ECCS staff score the student's performance using a rubric, which focuses on several interview dimensions, such as, first impressions, appearance, non-verbal behaviours, responsiveness, communication skills, preparation, and ability to demonstrate their accomplishments specific to the job posting. The rubrics are reviewed by the instructors to assign an appropriate grade and are uploaded to the learning management system for the students to review.

Each student interview is digitally recorded and uploaded to a confidential online drop-box for the student to watch. The recording of the interview serves two purposes: first, if a student challenges the rubric grade of the mock interview, the instructor can watch the video and consider revising the grade, if warranted. This type of review by the instructor is rarely requested, with approximately $4 \%$ of the students requesting a review over the previous three years. The second purpose, of the video-recorded mock interview is to allow students to watch and be able to assess themselves after the experience. Researchers have shown that college students benefit from videotaped mock interview training. Results indicate significant improvement in interview performance, self-evaluation, and assertiveness for experimental groups [6].

2.2.4 Active Learning (20\%). Throughout the term students complete a number of experiential activities reinforcing the course concepts and increasing skill development. They include problem-solving exercises, informal group work, role-playing and critiques of peer work. Additionally, students are assigned homework and reflection exercises and a few short unannounced quizzes. All these assessment items carry a weight of $20 \%$. This grade component improves student attendance and engagement with the course materials and instructional staff.

2.2.5 Comprehensive Final Examination (25\%). The final exam is application focused with a number of short answer questions that require the students to apply the course concepts and material to real-life career development scenarios.

\section{FEEDBACK AND CHALLENGES}

Course evaluation surveys suggest students are generally very satisfied with the course. The confidential online course evaluation is open for students to complete during the last two weeks of classes. The survey incorporates seven questions using Likert scale response options and an invitation to include free-form narrative comments. The course data is tabulated and presented to 
instructors in a summary report. The breakdown for each year is as follows:

- 2012 had a total of 138 students enrolled across three sections, with one instructor teaching two sections with a total of 85 students and another instructor had the remaining 53 students in a third section. The overall term-end course evaluation response rate was $73 \%$.

- 2013 had a total of 172 students enrolled across four sections, with one instructor teaching two sections for a total of 99 students and the other instructor with two sections, for a total of 73 students. The overall termend course evaluation response rate was 58\%.

- 2014 had a total of 160 students enrolled, with four instructors each teaching one section, with $26,28,37$, and 69 students respectively in each section. The overall term-end course evaluation response rate was $63 \%$.

Figure 2 graphically depicts the results pertaining to the effectiveness of the instructor, as evaluated by the students. The graph shows the average aggregate score across the available sections for the year indicated with a confidence interval built from the standard deviation between the sections. On average, the effectiveness of the course instruction has improved in 2014 compared to the previous two years. Instructor effectiveness has also become more consistent among sections over the same time period. Statistical significance was not determined, because individual student responses are required and they are not readily available in the provided summary course evaluation reports.

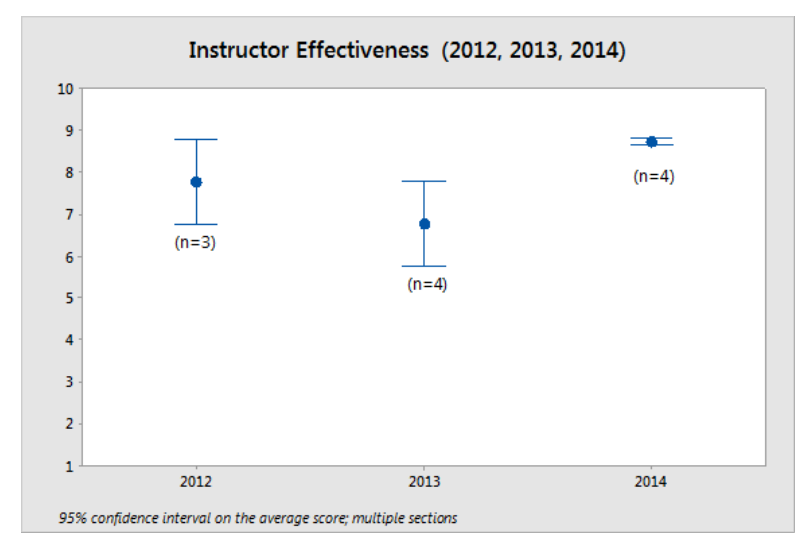

Figure 2: Instructor Effectiveness

Figure 3 depicts the graphical results of the question: "Overall, how do you rate the value of this course compared with others you have taken at McMaster?" The graph shows the average aggregate score across the available sections for the year indicated with a confidence interval built from the standard deviation between the sections. On average, the students perceived value of the course in the program has increased in 2014 compared to the previous two years. The students perceived value of the course in the program has also become more consistent among sections over the same time period. Statistical significance was not determined, because individual student responses are required and they are not readily available in the provided reports.

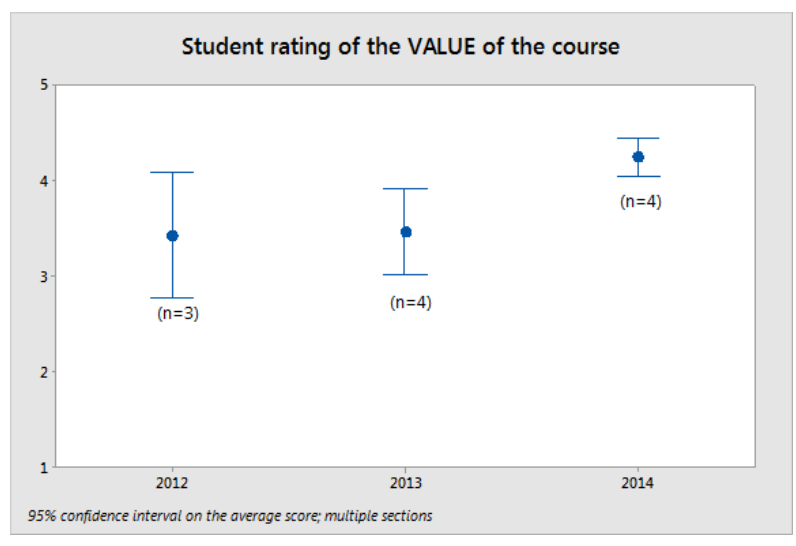

Figure 3: Student Rating of Course Value

The data from the other five questions from term-end course evaluations were not included, as they focus more on course administrative factors, such as feedback on progress, course organization, assessment fairness, etc. Traditionally the university administration evaluate instructor and course performance by reviewing summary data from the aforementioned questions only. Further a qualitative analysis of the free-form narrative comments from the 2014 term-end course evaluations revealed that:

- The overwhelming majority of students were positive and supportive towards the course. Comments included the following: "very well designed course", "concepts learned are very applicable", "professors and IA's were excellent and extremely helpful", "after most classes I felt good about myself, my program and my future. This course really helps students who need a little push like myself to start searching for coop and focusing on your professional academic career", "really helpful in getting the resume and cover letter ready for applying to jobs. The topics taught gave me a great insight into what to expect when applying and being successful in the coop job," and "if anyone did not do well in this course (myself actually...), it is their fault only, these profs are great and did their best to make sure everyone succeeded (while still being fair and professional)."

- There were a few concerns expressed of contradicting opinions between GENTECH 2PW3 instructors and IA's and the ECCS career advisors of the course material. Some indicative comments were, "felt there 
may be some ambiguity when it comes to emphasis of concepts between the professors and ECCS", "the ECCS staff said different things than the instructor and the IA's said different things as well", "need better consistency of information given to students by the professor and ECCS" and "need more consistency between ECCS staff. Some staff may tell you to change aspects of your resume that others may not, and some tell you a format is unacceptable while others say it is acceptable - more standardization.”

\subsection{Instructor and Instructional Assistant Feedback}

Instructors and Instructional Assistants were invited to offer their feedback in a post-mortem style meeting at the end of the 2014 term. We followed a semi-structured focus group approach. A qualitative analysis of the results revealed the following themes:

- $\quad$ The importance of quality checks of marking across sections and comparing and contrasting grades. The instructor group felt the exercise of pre-grading five assignments and then discussing the results and interpretation of the rubric within the instructor team was tremendously valuable. This process helped ensure consistent marking of assignments across all sections.

- The introduction of Instructional Assistants in the 2014 course offering was also something that was lauded by the instructor team and was recommended to continue. The IA's helped with ensuring consistency across sections, especially around messaging to students. They had the benefit of communication among different course sections. In some case the students felt the IA's were more approachable, because they did not have the same level of authority as instructors. Lastly, there was a perception that because only this course has Instructional Assistants, it must valuable, which contributed to student success.

- The team felt it was particularly important for the instructors to manage student expectations around the outcomes and grades of the career package assignment. Generally, students had a difficult time understanding their career package was a dynamic document which needed continuous improvement and customization for particular employment opportunities. Some students falsely believed a good grade on their career package assignment translated to being offered an employment interview. The instructor group recognized shifting student perceptions of academic success translating to realworld success in the competitive talent acquisition realm is difficult and will require overcommunication.

\subsection{Course Administrative Challenges}

There are several challenges administrating an experiential career development course delivered and supported by a multidisciplinary team for all level 2A students.

- Administrative time in planning and coordinating the logistics is substantial. It resulted in considerable extra hours outside the normal work duties for both the lead instructor and Management Chair. The communication and coordination among the three sessional instructors and the two instructional assistants; booking industry speakers and senior students for presentation across all the course sections; organizing ECCS engagement in delivering interview workshops, training days and coordinating the mock interview schedule; all these elements required considerable time and effort. There is also a need for extra administrative support to transfer and upload 160 interview videos to the online drop-box.

- There is a much heavier burden on the instructors compared to "standard" management course with grading content rich assignments on tight timelines, plus preparing and delivering numerous active learning exercises and activities.

- The addition of three new Sessional Instructors and two Instructional Assistants in 2014 required resources directed to talent acquisition, selection, onboarding and extensive program knowledge training. There was also considerable extra cost to hire IA's for 260 hours every term.

- The GENTECH 2PW3 course puts considerable pressure on the University's ECCS department during the fall term, which is in addition to them supporting the B.Eng. coop program. Only three ECCS staff are assigned to B.Tech; however, the interview workshops required between 3-7 staff facilitators (depending on section enrolment). The completion of 160 mock interviews within the last three weeks of the course requires additional personnel. This causes the ECCS Manager to deploy the entire staff of seven to meet these additional accountabilities.

\section{CONCLUSIONS AND FUTURE RESEARCH}

Notwithstanding the administrative challenges and the extensive coordination required to deliver the GENTECH 2PW3 course, it has been largely successful in achieving its objectives. The term-end course evaluations suggest the majority of the students find the course valuable and perceive the course as providing them with the necessary 
knowledge and skills to successfully complete the mandatory cooperative educational program requirement. The data also suggests the course instruction has improved throughout the past three years and the instruction and learning outcomes have become more consistent across sections. However, further research is required to better understand student learning and longevity of course outcomes.

It would be very interesting for future research projects to examine whether there is indeed a correlation between student performance in GENTECH 2PW3 and the likelihood of succeeding with their coop search and interviews. A longitudinal type of study, with pre- and post- assessments throughout a student's B.Tech undergraduate program would be required to more objectively assess whether the course is a major contributing factor for student success in obtaining and retaining cooperative workplace experiences. It would be challenging to analyze the outcome of a career course given the ethical constraints and the number of uncontrolled variables. This type of data, however, would be invaluable to course instructors and administrators of similar courses.

\section{Acknowledgments}

The author wishes to acknowledge the dedicated instructors and instructional assistants of GENTECH 2PW3, Poorna Gubbala, Carolyn Hudson, Hoda Kamel, Glen Matadeen, Alan Murray and Greg Zilberbrant. Special thanks to Jeff Ollinger, Manager of ECCS and the support of his team. The author is also indebted to Theomary Karamanis and Karen Lawrence for their review of and feedback on this paper.

\section{References}

[1] McMaster University Undergraduate Program Self-Study of Bachelor of Technology - Four Year Degree/Diploma Program, Institutional Quality Assurance Report, pp. 3, December 2013.

[2] Sheri Dressler and A. E. Keeling, Student benefits of cooperative education. In Richard Coll \& Chris Eames (Eds). International handbook for cooperative education: An international perspective of the theory, research and practice of work-integrated learning. Boston, MA: World Association for Cooperative Education, 2004, 225 pp.

[3] Duane Brown, Career Information, Career Counseling, and Career Development. Toronto, ON: Pearson Education, 2006 (9th ed.), \{ISBN: 978-0205-49841-3\}

[4] David A. Kolb, Experiential learning: Experience as the source of learning and development. Englewood Cliffs, NJ, Prentice Hall, 1984, \{978-0132-95261-3\}
[5] Todd Maurer, Jerry Solamon, and Michael Lippstreu, "How does coaching interviewees affect the validity of a structured interview?” Journal of Organizational Behavior, vol. 29, no 3, pp. 355-371, April 2008.

[6] Margaret Austin and Thomas Grant, "Interview training for college students disadvantaged in the labor market: Comparison of five instructional techniques," Journal of Counseling Psychology, vol. 28, no 1, pp. 72-75, January 1981. 